Ambiente \& Água - An Interdisciplinary Journal of Applied Science
ISSN 1980-993X - doi:10.4136/1980-993X
www.ambi-agua.net
E-mail: ambi-agua@agro.unitau.br

\title{
Estado trófico em uma seção do rio Catolé Grande sob diferentes níveis de vazão
}

\author{
doi: 10.4136/ambi-agua.1231
}

Received: 25 Oct. 2013; Accepted: 22 Apr. 2013

\section{Luciano Vieira Barreto $^{1}$; Micael de Souza Fraga ${ }^{2}$; Flávia Mariani Barros ${ }^{1}$; Felizardo Adenilson Rocha ${ }^{3}$; Jhones da Silva Amorim ${ }^{1}$; Stênio Rocha de Carvalho ${ }^{1}$; Paulo Bonomo ${ }^{1}$; Danilo Paulúcio da Silva ${ }^{1}$}

\author{
${ }^{1}$ Universidade Estadual do Sudoeste da Bahia (UESB), Itapetinga, BA, Brasil \\ ${ }^{2}$ Universidade Federal de Viçosa (UFV), Viçosa, MG, Brasil \\ Departamento de Engenharia Agrícola \\ ${ }^{3}$ Instituto Federal da Bahia (IFBA), Vitória da Conquista, BA, Brasil \\ *Autor correspondente: e-mail: micaelfraga@yahoo.com.br, \\ lucianoengenheiroambiental@yahoo.com.br, mariamariani@yahoo.com.br, \\ felizardoar@hotmail.com,jhones_sa@hotmail.com,steniophn@ hotmail.com, \\ bonomopaulo@gmail.com,danilopaulucio@gmail.com
}

\section{RESUMO}

Este estudo teve como objetivo avaliar, por meio de duas metodologias distintas, o estado trófico do rio Catolé Grande sob diferentes níveis de vazão em uma seção transversal próxima ao ponto onde a água é captada para abastecer a cidade de Itapetinga no estado da Bahia, Brasil. As amostras de água foram coletadas em diferentes meses, correspondendo a diferentes níveis de vazão. A classificação do estado trófico rio Catolé Grande foi realizada usando as duas metodologias distintas, ambos com base no valor de fósforo. A vazão foi com base no produto da velocidade pela área da secção transversal. Os resultados mostraram classificações tróficas muito altas na seção avaliada, com os maiores índices de estado trófico associados a maiores níveis de vazão. A classificação da seção foi hipertrófica entre janeiro e julho de 2011, pelas duas metodologias, no entanto, no período de agosto a novembro, do mesmo ano, houve diferenças na classificação trófica. Considerando-se a média de todo o período de estudo, a seção avaliada foi classificada como hipereutrófica, independentemente da metodologia utilizada.

Palavras-chave: monitoramento, qualidade de água, eutrofização.

\section{Trophic state in the Catolé Grande River under different streamflow rates}

\begin{abstract}
This study evaluated the trophic state of Catole Grande River under different streamflow levels in a cross section near the uptake point for the water supply of the town of Itapetinga, in
\end{abstract}


Bahia State, Brazil. Water samples were collected in different months, corresponding to different streamflow levels. The Catolé Grande River's trophic state classification was performed using two distinct methodologies, both based on phosphorus content. The streamflow was calculated by the product of velocity by cross section area. The results showed very high trophic classifications at the evaluated section, with the high levels of trophic status associated with high streamflows. The water classification at this section was hypertrophic between January and July of 2011, by both methodologies; however, from August to November of the same year, there were differences in trophic classification. Considering the average of the entire study period, the section was classified as hypereutrophic, regardless of the methodology used.

Keywords: monitoring, water quality, eutrofization.

\section{INTRODUÇÃO}

O carreamento de parte dos fertilizantes utilizados em culturas agrícolas e a grande carga de efluentes residenciais e industriais têm levado corpos hídricos a uma condição de desequilíbrio em termos de disponibilidade de nutrientes. Quando em concentrações superiores àquelas consideradas como normal nos meios aquáticos, os nutrientes podem provocar mudanças em suas características, podendo afetar os diversos usos da água, os quais vão desde a preservação das vidas aquáticas até o consumo humano, fenômeno este, conhecido como eutroficação antrópica (Farage et al., 2010).

O nitrogênio e o fósforo presentes nos rios e lagos são nutrientes de grande importância à cadeia alimentar. Conforme Esteves (1998), o fósforo é considerado um importante poluente de cursos de água, principalmente águas superficiais continentais.

O fósforo, em níveis exercíveis na água, favorece o crescimento de algas e plantas que interferem na utilização da água para consumo humano ou recreação. Dentre os fatores que influenciam a eutrofização, além das concentrações de fósforo e nitrogênio, podem ser citados a velocidade da água, a vazão, a turbidez, a profundidade do curso de água, a temperatura, entre outros (Lamparelli, 2004; Mansor, 2005).

Em sistemas agrícolas, a utilização inadequada de adubos orgânicos e minerais pode provocar o excesso de importantes nutrientes nos solos, que podem chegar aos cursos d'água devido a processos como lixiviação e escoamento superficial (Corriveau et al., 2009).

Determinar o estado trófico de um corpo hídrico é fundamental para obtenção de informações sobre o mesmo. Nesse contexto, o índice de estado trófico (IET) é amplamente utilizado em diversos trabalhos. Esse índice estabelece níveis de trofia em relação às concentrações de fósforo total e clorofila, possibilitando a classificação das águas em classes tróficas. Segundo Lamparelli (2004), dentre as variáveis estabelecidas para cálculo do IET, o fósforo total é a mais importante, pois este nutriente é, na maioria das vezes, o fator limitante para a produção primária.

Basicamente, o estado trófico de um corpo de água pode ser classificado como oligotrófico, mesotrófico e eutrófico, podendo haver subdivisões.

Ambientes oligotróficos podem ser entendidos como aqueles que apresentam baixas concentrações de nutrientes e baixas produtividades primárias. Ambientes mesotróficos apresentam produtividade intermediária, com possíveis implicações sobre a qualidade da água, mas em níveis aceitáveis na maioria dos casos. Ambientes eutróficos apresentam alto nível de produtividade e são ricos em matéria orgânica e elementos minerais (nutrientes), tanto em suspensão quanto na região bentônica (Mansor, 2005). 
Um dos impactos mais preocupantes da aceleração do processo de eutrofização é o aumento da probabilidade de ocorrência de florações de algas, principalmente as cianobactérias potencialmente tóxicas, as quais podem alterar a qualidade das águas, sobretudo no que tange ao abastecimento público.

Em um estudo sobre a qualidade das águas córrego Rico em Jaboticabal-SP, utilizando o IET, Zanini et al. (2010) encontraram águas com baixa classificação trófica na região da nascente. No médio córrego Rico, após lançamentos de fontes pontuais de contaminação, como esgotos domésticos e efluentes de suinocultura, ocorreu um aumento nos valores de IET, ocasionado provavelmente devido à grande quantidade de fósforo total nestes efluentes. No terceiro ponto de coleta os autores ressaltam que o IET diminuiu, provavelmente devido à diluição do fósforo e pelo fenômeno da autodepuração do curso de água.

Alves et al. (2012), estudando a qualidade das águas e o estado trófico do rio Arari na Ilha de Marajó, encontraram altos valores de trofia para o rio em estudo. Os autores salientam que a alta classificação também foi consequência das grandes quantidades de nutrientes nas águas, principalmente o fósforo total. Porém, o mesmo alega que o rio Arari está em processo de eutrofização natural, pois os lançamentos de efluentes e as contaminações antrópicas ainda são muito incipientes.

A caracterização do estado trófico de cursos d'água torna-se essencial, uma vez que permite avaliar a efetividade das ações de gerenciamento implementadas, bem como estabelecer medidas pertinentes e corretivas necessárias. Diante disso, o objetivo deste trabalho foi avaliar o estado trófico em uma seção transversal do rio Catolé Grande, em função da vazão, por meio de duas metodologias, bem como verificar a influência da vazão nos valores do índice de estado trófico.

\section{MATERIAL E MÉTODOS}

\subsection{Caracterização da área de estudo}

O local do presente estudo está situado no rio Catolé Grande, sendo esta pertencente a bacia do rio Pardo. Considerando o sistema de projeção Universal Transversa de Mercator (UTM), a bacia está contida na zona 24, entre os paralelos N: $8380000-8226000$ e meridianos E: 300000 - 385000, estando integralmente localizada na região sudoeste da Bahia.

O rio Catolé Grande nasce no planalto de Vitória da Conquista, próximo à cidade de Barra do Choça, e dirige-se à calha do rio Pardo, no sentido Nordeste-Sudeste, com seção de controle a jusante à cidade de Itapetinga.

Para o estudo foi utilizada uma seção transversal do rio Catolé Grande de aproximadamente 28 metros de largura (Figura 1). Esta fica à aproximadamente 50 metros, a montante, do ponto de coleta de água para abastecimento público no município de Itapetinga, Bahia.

A seção transversal do rio Catolé Grande em estudo se situa na região do baixo Catolé. Segundo Lima e Pinto (2011) a porção drenada pelo baixo curso do rio Catolé Grande é caracterizada por níveis altimétricos que variam de 260 a 400 metros, apresentando relevo plano a suavemente ondulado. O clima varia de semi-árido a sub-úmido, com solos predominantemente do tipo Argissolos Vermelho Amarelos com pequenas manchas de floresta estacional decidual. No que tange as atividades econômicas, a região do baixo Catolé é ocupada pela atividade agropastoril extensiva 


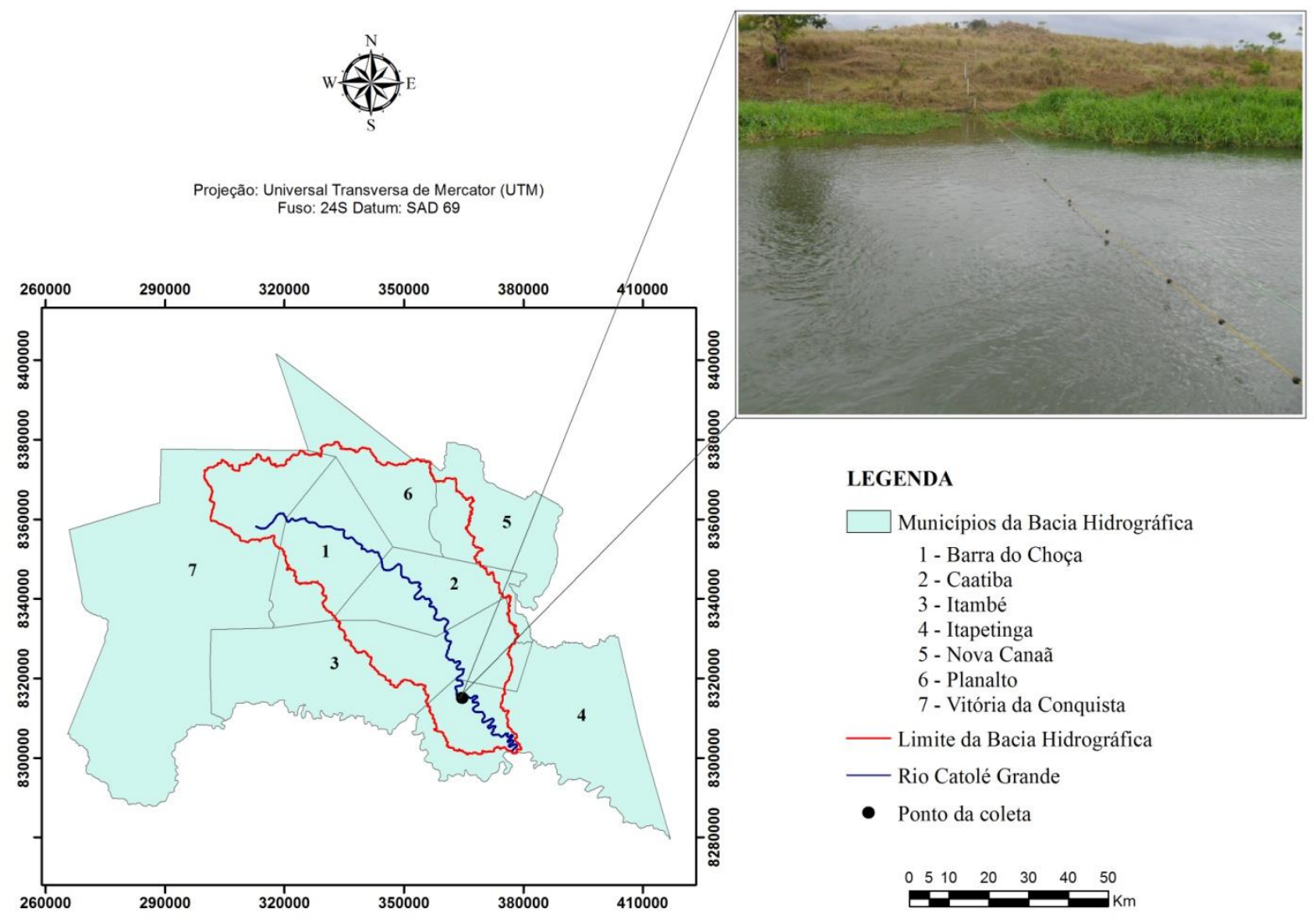

Figura 1. Seção transversal do rio Catolé Grande em estudo.

\subsection{Metodologia de coleta e análise das amostras de água}

As coletas foram realizadas em oito campanhas anuais. Estas foram feitas no verão (07/01/2011 e 11/02/2011), outono (15/04/2011 e 14/05/2011), inverno (10/07/2011 e 20/08/2011) e na primavera (02/10/2011 e 05/11/2011). Para cada data de amostragem foram realizadas três repetições em cada ponto.

$\mathrm{Na}$ seção transversal em estudo foram definidos três pontos de coleta de amostras de água: margem esquerda do rio (e), centro do rio (c) e margem direita do rio (d).

As amostragens de água foram realizadas por integração vertical com o auxilio de um amostrador de sedimentos em suspensão, modelo UDSH-48, sendo posteriormente acondicionadas em garrafas apropriadas e preservadas segundo metodologia descrita em APHA et al. (2005). Em seguida, estas amostras foram transportadas diretamente para o Laboratório de Solos da Universidade Estadual do Sudoeste da Bahia, onde foram efetuadas as análises.

Em cada amostra foram quantificadas as concentrações de fósforo total (PT) de acordo com a metodologia descrita em Matos (2004).

\subsection{Determinação da vazão do rio Catolé Grande}

As medições das velocidades e da área da seção transversal do rio Catolé Grande foram realizadas em todas as coletas de campo.

A velocidade da água em cada ponto de amostragem foi determinada com o auxílio de um molinete hidrométrico. As posições horizontais e verticais do molinete, para a determinação da velocidade média, foram definidas de acordo com a largura e profundidade do curso de água, conforme metodologias descritas em Almeida (2006) (Tabela 1) e Pruski et al. (2006) (Tabela 2), respectivamente. 
Tabela 1. Largura do curso d'água e intervalo entre as distancias horizontais recomendáveis para $\mathrm{o}$ posicionamento do molinete.

\begin{tabular}{cc}
\hline $\begin{array}{c}\text { Largura do curso } \\
\text { d'água }(\mathrm{m})\end{array}$ & $\begin{array}{c}\text { Intervalo } \\
(\mathrm{m})\end{array}$ \\
\hline Até 3 & 0,20 \\
3 a 6 & 0,50 \\
6 a 15 & 1,00 \\
15 a 30 & 2,00 \\
30 a 80 & 4,00 \\
80 a 150 & 6,00 \\
150 a 250 & 8,00 \\
$>250$ & 12,00 \\
\hline
\end{tabular}

Tabela 2. Profundidade recomendada para o posicionamento do molinete de acordo com a profundidade do perfil do curso d'água $(\mathrm{H})$ e as equações para cálculo da velocidade média (VM).

\begin{tabular}{cll}
\hline $\begin{array}{c}\text { Profundidade do rio } \\
(\mathrm{m})\end{array}$ & $\begin{array}{c}\text { Profundidade da medição } \\
(\mathrm{m})\end{array}$ & \multicolumn{1}{c}{$\begin{array}{c}\text { Equação para o cálculo da } \\
\text { VM }\end{array}$} \\
\hline $\mathrm{H} \leq 0,60$ & $0,6 \mathrm{H}$ & $\mathrm{VM}_{0,2 \mathrm{H}}$ \\
$0,60 \leq \mathrm{H} \leq 1,20$ & $0,2 \mathrm{H} \mathrm{e} 0,8 \mathrm{H}$ & $\left(\mathrm{VM}_{0,2 \mathrm{H}}+\mathrm{VM}_{0,8 \mathrm{H}}\right) / 2$ \\
$1,20 \leq \mathrm{H} \leq 2,00$ & $0,2 \mathrm{H} 0,6 \mathrm{H} \mathrm{e} 0,8 \mathrm{H}$ & $\left(\mathrm{VM}_{0,2 \mathrm{H}}+2 \mathrm{VM}_{0,6 \mathrm{H}}+\mathrm{VM}_{0,8 \mathrm{H}}\right) / 4$ \\
\hline
\end{tabular}

A área da seção transversal foi obtida por meio de levantamento batimétrico local. A vazão do curso de água foi obtida pelo produto da velocidade média do escoamento pela área da seção transversal.

\subsection{Determinação do índice de estado trófico}

Duas metodologias relacionadas à variável fósforo foram empregadas para a classificação do nível de trofia no rio Catolé Grande. A primeira refere-se à proposta por Carlson (1977) modificado por Toledo Jr. et al. (1983), conforme a Equação 1, para ambientes lênticos de clima tropical.

$$
\mathrm{IET}_{\mathrm{T}}=10 \times\left(6-\left\{\frac{\ln [80,32 / \mathrm{PT}]}{\ln 2}\right\}\right)
$$

em que:

IET $_{\mathrm{T}}$ : índice de estado trófico em relação à variável fósforo total para ambientes lênticos segundo metodologia proposta por Carlson (1977) e modificado por Toledo Jr. et al. (1983);

PT: concentração de fósforo total $\left(\mu \mathrm{g} \mathrm{L}{ }^{-1}\right)$.

Para classificar os níveis tróficos conforme a modificação de Toledo Jr. et al. (1983), foram adotadas as categorias apresentadas na Tabela 3. 
Tabela 3. Valores dos limites das concentrações de fósforo total para os diferentes níveis tróficos, segundo o sistema de classificação proposto por Carlson (1977) e modificado por Toledo Jr et al. (1983).

\begin{tabular}{ll}
\hline Estado trófico & Ponderação \\
\hline Ultraoligotrófico & IET $\leq 24$ \\
Oligotrófico & $24<$ IET $\leq 44$ \\
Mesotrófico & $44<$ IET $\leq 54$ \\
Eutrófico & $54<$ IET $\leq 74$ \\
Hipereutrófico & IET $>74$ \\
\hline
\end{tabular}

Fonte: Adaptado de Toledo Jr. et al.(1983); Barros (2008).

A segunda refere-se à metodologia proposta pó Lamparelli (2004), que diferencia o índice de estado trófico para ambientes lênticos e lóticos (Equação 2), como também propõe uma nova classificação trófica observada na Tabela 4.

$$
\operatorname{IET}_{\mathrm{L}}=10 \times\left(6-\left\{\frac{0,42-0,36 \times[\ln \mathrm{PT}]}{\ln 2}\right\}\right)-20
$$

em que:

$\mathrm{IET}_{\mathrm{L}}$ : Índice de estado trófico em relação à variável fósforo total para ambientes lóticos segundo metodologia proposta por Lamparelli (2004);

PT: concentração de fósforo total $\left(\mu \mathrm{g} \mathrm{L}{ }^{-1}\right)$.

Tabela 4. Valores dos limites das concentrações de fósforo total para os diferentes níveis tróficos (Lamparelli, 2004).

\begin{tabular}{ll}
\hline Estado trófico & Ponderação \\
\hline Ultraoligotrófico & IET $\leq 47$ \\
Oligotrófico & $47<$ IET $\leq 52$ \\
Mesotrófico & $52<$ IET $\leq 59$ \\
Eutrófico & $59<$ IET $\leq 63$ \\
Supereutrófico & $63<$ IET $\leq 67$ \\
Hipereutrófico & IET $>67$ \\
\hline
\end{tabular}

Fonte: Adaptado de Lamparelli (2004).

Comparando os valores de IET, obtidos pelas Equações 1 e 2, com os valores das Tabelas 3 e 4, foram feitas as classificações do estado trófico para o local avaliado no rio Catolé Grande. 


\section{RESULTADOS E DISCUSSÃO}

Na Tabela 5 estão apresentados, para cada data de coleta, os valores das vazões, os valores dos índices dos estados tróficos (IET) relacionados à variável fósforo total, bem como suas respectivas classificações tróficas.

Tabela 5. Concentrações de fósforo total, valores do IET e estados tróficos, segundo as metodologias propostas por Toledo Jr et al. (1983) e Lamparelli (2004), correspondentes às coletas no lado direito (d), centro (c) e lado esquerdo (e) da seção transversal do rio Catolé Grande e suas respectivas vazões.

\begin{tabular}{|c|c|c|c|c|c|c|}
\hline $\begin{array}{c}\text { Mês da } \\
\text { coleta }\end{array}$ & $\begin{array}{l}\text { Vazão } \\
\left(\mathrm{m}^{3} \mathrm{~s}^{-1}\right)\end{array}$ & $\frac{\text { PT }}{\left(\mu g \mathrm{~L}^{-1}\right)}$ & $\begin{array}{c}\text { IET } \\
\text { (Toledo Jr. et } \\
\text { al., 1983) } \\
\end{array}$ & $\begin{array}{c}\text { Classificação } \\
\text { Trófica }\end{array}$ & $\begin{array}{c}\text { IET } \\
\text { (Lamparelli, } \\
\text { 2004) } \\
\end{array}$ & $\begin{array}{c}\text { Classificação } \\
\text { trófica }\end{array}$ \\
\hline $\operatorname{Jan}(d)$ & \multirow{4}{*}{8,17} & 1800 & 104,86 & Hipereutrófico & 72,87 & Hipereutrófico \\
\hline $\operatorname{Jan}(\mathrm{c})$ & & 1800 & 104,86 & Hipereutrófico & 72,87 & Hipereutrófico \\
\hline $\operatorname{Jan}(\mathrm{e})$ & & 1300 & 100,17 & Hipereutrófico & 71,18 & Hipereutrófico \\
\hline Média & & 1633,33 & 103,46 & Hipereutrófico & 72,36 & Hipereutrófic \\
\hline Fev (d) & \multirow{4}{*}{6,47} & 1600 & 103,16 & Hipereutrófico & 72,26 & Hipereutrófico \\
\hline Fev (c) & & 200 & 73,16 & Eutrófico & 61,46 & Eutrófico \\
\hline $\mathrm{Fev}(\mathrm{e})$ & & 1100 & 97,76 & Hipereutrófico & 70,31 & Hipereutrófico \\
\hline Média & & 966,67 & 95,89 & Hipereutrófico & 69,64 & Hipereutrófic \\
\hline $\operatorname{Abr}(d)$ & \multirow{4}{*}{7,97} & 4200 & 117,08 & Hipereutrófico & 77,27 & Hipereutrófico \\
\hline $\operatorname{Abr}(\mathrm{c})$ & & 200 & 73,16 & Eutrófico & 61,46 & Eutrófico \\
\hline $\operatorname{Abr}(\mathrm{e})$ & & 900 & 94,86 & Hipereutrófico & 69,27 & Hipereutrófico \\
\hline Média & & 1766,66 & 104,59 & Hipereutrófico & $\mathbf{7 2 , 7 7}$ & Hipereutrófic \\
\hline Mai (d) & \multirow{4}{*}{8,29} & 5200 & 120,16 & Hipereutrófico & 78,38 & Hipereutrófico \\
\hline Mai (c) & & 800 & 93,16 & Hipereutrófico & 68,66 & Hipereutrófico \\
\hline Mai (e) & & 3900 & 116,02 & Hipereutrófico & 76,89 & Hipereutrófico \\
\hline Média & & 3300 & 113,61 & Hipereutrófico & 76,02 & Hipereutrófic \\
\hline Jul (d) & \multirow{4}{*}{6,58} & 2200 & 107,16 & Hipereutrófico & 73,91 & Hipereutrófico \\
\hline $\mathrm{Jul}(\mathrm{c})$ & & 700 & 91,24 & Hipereutrófico & 67,97 & Hipereutrófico \\
\hline Jul (e) & & 200 & 73,16 & Eutrófico & 61,46 & Eutrófico \\
\hline Média & & 1033,33 & 96,85 & Hipereutrófico & 69,99 & Hipereutrófic \\
\hline Ago (d) & \multirow{4}{*}{5,08} & 120 & 65,79 & Eutrófico & 58,81 & Mesotrófico \\
\hline Ago (c) & & 120 & 65,79 & Eutrófico & 58,81 & Mesotrófico \\
\hline Ago (e) & & 55 & 54,54 & Eutrófico & 54,75 & Mesotrófico \\
\hline Média & & $\mathbf{9 8 , 3 3}$ & 62,92 & Eutrófico & 57,77 & Mesotrófico \\
\hline Out (d) & \multirow{4}{*}{5,58} & 400 & 83,16 & Hipereutrófico & 65,06 & Supereutrófico \\
\hline Out (c) & & 300 & 79,01 & Hipereutrófico & 63,56 & Hipereutrófico \\
\hline Out (e) & & 500 & 86,38 & Hipereutrófico & 66,22 & Supereutrófico \\
\hline Média & & 400 & 83,16 & Hipereutrófico & 65,06 & Supereutrófic \\
\hline Nov (d) & \multirow{4}{*}{3,98} & 200 & 73,16 & Eutrófico & 61,46 & Eutrófico \\
\hline Nov (c) & & 100 & 63,16 & Eutrófico & 57,86 & Mesotrófico \\
\hline Nov (e) & & 200 & 73,16 & Eutrófico & 61,46 & Eutrófico \\
\hline Média & & 166,66 & 70,53 & Eutrófico & 60,51 & Eutrófico \\
\hline Média p. & 6,51 & 1170,62 & 98,65 & Hipereutrófico & 70,64 & Hipereutrófic \\
\hline
\end{tabular}


De acordo com os dados apresentados, as maiores vazões ocorreram nas coletas realizadas em maio e janeiro, correspondentes às estações do outono e verão, enquanto a menor vazão ocorreu na coleta realizada em novembro, correspondente à primavera.

Analisando a classificação trófica, não houve diferença em relação às duas diferentes metodologias para as coletas realizadas em janeiro, fevereiro, abril, maio, julho e novembro. A classificação trófica foi diferente, em relação às duas metodologias utilizadas, apenas para os meses de agosto e outubro.

Nas coletas realizadas em agosto, enquanto a qualidade da água foi classificada como eutrófica pelo índice de Carlson (1977) modificado por Toledo Jr. et al. (1983), pela metodologia de Lamparelli (2004) foi classificada como mesotrófica. Já nas coletas realizadas em outubro, o IET foi hipereutrófico pelo índice de Carlson (1977) modificado por Toledo Jr. et al. (1983) e supereutrófico pela metodologia de Lamparelli (2004).

Nota-se que a metodologia proposta por Carlson (1977) modificado por Toledo Jr. et al. (1983) tende a classificar o rio em classe de trofia superior à metodologia proposta por Lamparelli (2004). Este fato se deve devido a versão de Lampareli (2004) ter sido desenvolvida a partir de dados de ambientes lóticos, pois estes admitem maiores concentrações de fósforo total em seu ambiente devido ao fato da perda de nutrientes em seu ambiente ser maior do que em ambientes lênticos.

No período de janeiro a julho, pela classificação do IET, a seção do rio foi tida como hipereutrófica, já para o mês de outubro, a água foi classificada como eutrófica. Ambas as classificações foram independente da metodologia utilizada.

É importante ressaltar que a utilização de um índice simplificado de estado trófico e o estabelecimento de limites para as variáveis avaliadas são vantajosos, devido à utilização de variáveis de simples determinação e baixo custo analítico, como fósforo total, além de possibilitarem uma compreensão mais fácil do que um índice probabilístico. No entanto, para sua aplicação, é necessária uma avaliação criteriosa de sua composição (Lamparelli, 2004).

Segundo a resolução CONAMA $n^{\circ}$ 357/2005, para que um curso d'água esteja enquadrado como classe 2, avaliando apenas a concentração de fósforo, é necessário que a concentração de fósforo total seja inferior a $100 \mu \mathrm{g} \mathrm{L}^{-1} \mathrm{em}$ ambientes lóticos (Brasil, 2005). Nota-se que, em todas as amostragens, as concentrações de fósforo total observadas foram superiores aos valores estabelecidos pela referida resolução, este fato também foi observado por Barros (2008) para as águas do rio Turvo Sujo, MG.

Segundo Chapman (1992), as concentrações de fósforo, na maioria das águas naturais,

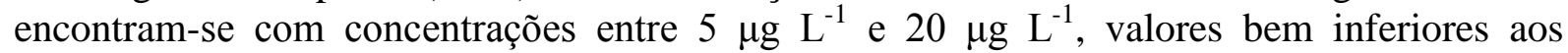
encontrados neste estudo.

Ainda de acordo com a Tabela 5, verifica-se que a concentração do fósforo total apresentou comportamento crescente em função do aumento da vazão, sendo esses valores refletidos no aumento do grau de trofia. Segundo Farage (2010), este aumento no aporte de fósforo total no corpo de água é justificável pelo mecanismo do escoamento superficial, frequentemente ocorrido nos períodos chuvosos, principalmente, em solos desprovidos de vegetação ou com predominância de cobertura rasteira. Esta condição possibilita o carreamento de grandes quantidades de material de solo para os corpos hídricos, aumentando os valores das concentrações de fósforo total. Segundo Koski-Vahala e Hartikainen (2001) e McDowell et al. (2001), em ambientes lóticos, o aumento das concentrações do fósforo também é causado pela ressuspensão dos sedimentos ocasionado pela turbulência da água.

Avaliando o Rio Turvo Sujo, Barros (2008) encontrou maiores concentrações de fósforo total no período chuvoso. Farage et al. (2010) avaliando trechos do rio Pomba, Silva et al. (2010) avaliando o rio São Francisco Falso e Cunha et al. (2008) avaliando o rio Canha também obtiveram o mesmo tipo de resultado. No presente trabalho, o comportamento sazonal do fósforo foi semelhante ao observado pelos autores supracitados. 
Contudo, em uma avaliação das concentrações de nutrientes em diversos rios do estado de São Paulo, Lamparelli (2004) indicou, em seu estudo, que não há diferença significativa entre as concentrações de fósforo total, referente às águas de 35 rios avaliados, para os períodos seco e chuvoso. A mesma autora ainda salienta que, embora as chuvas contribuam para o aumento do escoamento superficial e, consequentemente, para o incremento das concentrações de fósforo nos corpos hídricos, as chuvas também provocam um aumento do volume de água nos rios, aumentando assim o potencial de diluição de cargas poluidoras. Essa fato também foi observado por Cunha et al. (2008) para o rio Pariquera-Açu, uma vez que os autores não conseguiram encontrar um padrão defino para a variação sazonal nas concentrações de fósforo total.

Os centros populacionais situados às margens do rio Catolé Grande também contribuem para aumento na concentração de fósforo. Para o ponto em estudo, destaca-se a forte influência do município de Itapetinga. Verifica-se que a degradação da qualidade da água se deve às atividades agropecuárias da região, que interferem na cobertura da terra, bem como aos resíduos gerados pela população urbana, que se traduzem em fontes difusas e pontuais de poluição.

Segundo Smith e Schindler (2009), a eutrofização pode levar à alteração no sabor, no odor, na turbidez e na cor da água, bem como a redução do oxigênio dissolvido, provocando crescimento excessivo de plantas aquáticas, mortandade de peixes e outras espécies aquáticas, além do comprometimento das condições mínimas para o lazer na água.

As concentrações de fósforo conduzem à classificação do rio Catolé Grande como um ambiente com alto grau de trofia, para ambas as metodologias utilizadas. Deste modo deve-se estar atento aos riscos que poderão ser causados pela eutrofização, já que a área em questão está localizada próxima à estação de captação de água para abastecimento.

\section{CONCLUSÕES}

Tendo por base os resultados obtidos e ponderando as condições em que o estudo foi realizado, conclui-se que:

Os valores de fósforo total encontrados ficaram bem acima dos valores estabelecidos pela resolução CONAMA no 357/2005 para rios classe 2, exceto para o mês de agosto.

As maiores concentrações de fósforo estão associadas a maiores valores de vazão, apesar das vazões mais baixas também terem indicado altos graus de trofia.

Os valores do IET, para a seção avaliada do rio Catolé Grande, foram indicativos de estado de eutrofização, com tendência à hipereutrofização na maioria dos meses avaliados.

A metodologia proposta por Carlson (1977) modificado por Toledo Jr. et al. (1983) tendeu a classificar o rio em classe de trofia superior à metodologia proposta por Lamparelli (2004).

Observando a média anual dos valores de fósforo total, a seção avaliada do rio Catolé Grande foi classificada como hipereutrófica, independente da metodologia utilizada.

\section{REFERÊNCIAS}

ALMEIDA, T. V. D. Índice de qualidade da água e coeficientes de autodepuração de trechos do rio Pomba. 2006. 68 p. Dissertação (Mestrado em Engenharia Agrícola) Universidade Federal de Viçosa, Viçosa, 2006.

ALVES, I. C. C.; EL-ROBRINI, M.; SANTOS, M. L. S.; MONTEIRO, S. M.; BARBOSA, L. P. F.; GUIMARÃES, J. T. F. Qualidade das águas superficiais e avaliação do estado trófico do Rio Arari (Ilha de Marajó, norte do Brasil). Acta Amazonica, v. 42, n. 1, p. 115-124, 2012. http://dx.doi.org/10.1590/S0044-59672012000100014 
AMERICAN PUBLIC HEALTH ASSOCIATION - APHA; WATER WORKS ASSOCIATION - AWWA; WATER ENVIRONMENT FEDERATION - WEF. Standard methods for the examination of water and wastewater. 19. ed. New York, 2005. 1268 p.

BARROS, F. M. Dinâmica do nitrogênio e do fósforo e estado trófico nas águas do rio Turvo Sujo. 2008. 193 p. Tese (Doutorado em Engenharia Agrícola) - Universidade Federal de Viçosa, Viçosa, 2008.

BRASIL. Conselho Nacional de Meio Ambiente - CONAMA. Resolução n. ${ }^{\circ}$ 357, de 17 de março de 2005. Dispõe sobre a classificação dos corpos de água e diretrizes ambientais para o seu enquadramento, bem como estabelece as condições e padrões de lançamento de efluentes, e dá outras providências. Diário Oficial da República Federativa do Brasil, Brasília, 2005.

CARLSON, R. E. A trophic state index for lakes. Limnology and Oceanography, v. 22, p. 361-369, 1977.

CUNHA, D. G. F.; FALCO, P. B.; CALIJURI, M. C. Densidade fitoplanctônica e estado trófico dos rios Canha e Pariquera-Açu, bacia hidrográfica do Rio Ribeira do Iguape, SP, Brasil. Revista Ambiente \& Água, Taubaté, v. 3, n. 2, p. 90-104, 2008. http://dx.doi.org/10.4136/ambi-agua.55

CHAPMAN, D. (Ed.). Water quality assessment. A guide to the use of biota, sediments and water in environmental monitoring. 1. ed. London: Chapman \& Hall, 1992. 585p.

CORRIVEAU, J.; VAN BOCHOVE, E.; SAVARD, M. M.; CLUIS, D.; PARADIS, D. Occurrence of high in-stream nitrite levels in a temperate region agricultural watershed. Water Air Soil Pollution, v. 206, p. 335-347. 2009. http://dx.doi.org/10.007/s11270009-0109-6

ESTEVES, F. A. Fundamentos de limnologia. 2. ed. Rio de Janeiro: Interciência, 1998. $602 \mathrm{p}$.

FARAGE, J. A. P; MATOS, A T.; SILVA, D. D; BORGES; A. C. Determinação do índice de estado trófico para o fósforo em pontos do rio Pomba. Engenharia na Agricultura, Viçosa, v. 18, n. 4, p. 322-329, 2010.

KOSKI-VAHALA, J.; HARTIKAINEN, H. Assessment of the risk of phosphorus loading due to resuspended sediment. Journal of Environmental Quality, Madison, v. 30, p. 960-966, 2001. http://dx.doi.org/10.2134/jeq2001.303960x

LAMPARELli, M. C. Grau de trofia em corpos d'água do estado de São Paulo: avaliação dos métodos de monitoramento. 2004. 238 p. Tese (Doutorado em Ecologia Aplicada) - Universidade de São Paulo, São Paulo, 2004.

LIMA, E. M.; PINTO, J. E. S. S. Bacia do Rio Catolé, Bahia - Brasil: bases geoambientais e socioeconômicas para a gestão da água e do solo. Revista Geográfica de América Central, v. 1, p. 1-11, 2011. http://hdl.handle.net/11056/6234

MANSOR, M. T. C. Potencial de poluição de águas superficiais por fontes não pontuais de fósforo na bacia hidrográfica do ribeirão do Pinhal, Limeira-SP. 2005. 171 p. Tese (Doutorado em Engenharia Agrícola) - Universidade Estadual de Campinas, Campinas, 2005. 
MATOS, A. T. de. Práticas de qualidade do meio físico e ambiental. Viçosa: AEAGRI, 2004. 64 p. (Caderno Didático, 34)

McDOWELl, R. W.; SHARPleY, A. N.; CONDRON, L. M.; HAYGORTH, P. M.; BROOKES, P. C. Processes controlling soil phosphorus release to runoff and implications for agricultural management. Nutrient Cycling in Agroecosystems, v. 59, p. 269-284, 2001. http://dx.doi.org/10.1023/A:1014419206761

PRUSKI, F. F.; SILVA, D. D.; KOETZ, M. Estudo de vazão em cursos d'água. Viçosa: AEAGRI, 2006. 151 p. (Caderno Didático, 43).

SILVA, G. S.; MIOLA; S.; SILVA, G. S.; SOUSA, E. R. Avaliação da qualidade das águas do rio São Francisco Falso, tributário do reservatório de Itaipu, Paraná. Eclética Química, São Paulo, v. 35, n. 3, 2010. http://dx.doi.org/ 10.1590/S010046702010000300011

SMITH, V. H.; SCHINDLER, D. W. Eutrophication science: where do we go from here? Trends in Ecologyand Evolution, v. 24, n. 4, p. 201-207. 2009. http://dx.doi.org/10.1016/j.tree.2008.11.009

TOlEDO JR., A. P.; TALARICO, M.; CHINEZ, S. J.; AGUDO, E. G. A. A aplicação de modelos simplificados para a avaliação de processo da eutrofização em lagos e reservatórios tropicais. In: CONGRESSO BRASILEIRO DE ENGENHARIA SANITÁRIA, 1983, Camburiú. Anais... Camboriú: ABES, 1983.

ZANINI, H. L. H. T.; AMARAL, L. A.; ZANINI, J. R.; TAVARES, L. H. S. Caracterização da água da microbacia do córrego Rico avaliada pelo índice de qualidade de água e de estado trófico. Engenharia Agrícola, Jaboticabal, v. 30, n. 4, p. 732-741. 2010. http://dx.doi.org/10.1590/S0100-69162010000400017 